Journal Knowledge Industrial Engineering (JKIE)

\title{
INTEGRASI LINIER PROGRAMMING DAN PROGRAM DINAMIK UNTUK MENENTUKAN JUMLAH PRODUKSI KOPI YANG OPTIMUM DI UD. GADING MAS
}

\author{
(1)Novitasari, (2)M. Imron Mas'ud \\ (1) (2)Prodi Teknik Industri - Fakultas Teknik - Universitas Yudharta Pasuruan \\ Email koresponden : viethaimutz78@gmail.com
}

\begin{abstract}
Abstrak
Persaingan bisnis yang semakin ketat saat ini menuntut pelaku usaha untuk mengoptimasikan produknya agar mendapatkan keuntungan maksimum, salah satunya pada UD.Gading Mas yang merupakan salah satu Industri Kecil Menengah (IKM) yang mengelola kopi khas Kabupaten Pasuruan yang telah berproduksi untuk mengembangkan potensi sumber daya lokal daerah. Dalam mengembangkan ppotensi sumberdaya lokal, perusahaan mengalami masalah dalam menentukan jumlah produksi, sehingga perusahaan mengalami kelebihan produk.Dengan integrasi pendekatan Program Linier dan Program Dinamik diharapkan perusahaan dapat menentukan produksi dengan baik, sehingga tidak kelebihan maupun kekurangan produk.Dari hasil penelitian ini menunjukkan bahwa perencanaan dengan menggunakan program dinamik lebih menguntungkan.Dengan hasil tingkat produksi optimum sebesar 1.138 bungkus dengan pendapatan sebesar Rp. 22.760 .000 .
\end{abstract}

Kata kunci: Program Linier, Program Dinamis, Kopi, Produksi Optimal

\begin{abstract}
The increasingly fierce business competition is currently demanding business players to optimize their products to get the maximum profit, one of which is UD.Gading Mas, which is one of the Small and Medium Industries (IKM) which manages the typical coffee of Pasuruan Regency which has been producing to develop the potential of local resources area. In developing the potential of local resources, the company experienced problems in determining the amount of production, so the company experienced excess products. With the integration of the Linear Program and Dynamic Program approach, it is expected that the company can determine production well, so that neither excess or lack of product. From the results of this study indicate that the planning using a dynamic program is more profitable. With the optimum production level of 1,138 packs with an income of Rp. $22,760,000$.
\end{abstract}

Keywords: Linear Program, Dynamic Program, Coffee, Optimal Production

\section{PENDAHULUAN}

Era globalisasi seperti sekarang ini, persaingan bisnis yang semakin ketat menuntut industri dibidang manufaktur maupun jasa untuk meningkatkan strategi bisnisnya. Strategi bisnis yang lama belum tentu berhasil bila tetap diterapkan dimasa sekarang, sehingga perlu dikaji secara terus-menerus kinerjanya. Untuk itu industri-industri diharapkan mampu memahami sistem perencanaan produksi yang baik dan diharapkan mampu untuk terus meningkatkan efisiensi serta kemampuan untuk menghasilkan produk yang bermutu guna memenuhi pasar dan konsumen sehingga mendapatkan keuntungan yang optimum (Andi R. B, dkk, 2013). 
Kopi merupakan salah satu komoditi perkebunan yang diharapkan mampu meningkatkan nilai devisa ekspor Indonesia (Santoso, 1999). UD.Gading Mas merupakan salah satu Industri Kecil Menengah (IKM) yang mengelola kopi khas Kabupaten Pasuruan yang telah berproduksi untuk mengembangkan potensi sumber daya lokal daerah. UD. Gading Mas menerapkan sistem sistem make to stock yaitu memproduksi suatu produk jadi untuk disimpan, dan kebutuhan konsumen akan diambil dari persediaan di gudang penyimpanan. Permasalahan yang dihadapi oleh perusahaan adalah pihak perusahaan seringkali tidak dapat memperkirakan jumlah produksi yang tepat dalam memenuhi permintaan pasar.

Tabel : 1. Jumlah Produksi

\begin{tabular}{|c|c|c|c|c|c|c|c|c|c|}
\hline \multirow[b]{2}{*}{ Bulan } & \multicolumn{8}{|c|}{ Produk/Bungkus } & \multirow[b]{2}{*}{ Jumlah } \\
\hline & $\begin{array}{l}\text { Kopi } \\
\text { aroma }\end{array}$ & $\begin{array}{c}\text { Aluminium } \\
\text { foil }\end{array}$ & $\begin{array}{c}\text { Robusta } \\
\text { plastik }\end{array}$ & $\begin{array}{c}\text { Jahe } \\
\text { plastik }\end{array}$ & $\begin{array}{l}\text { Jahe } \\
\text { toples }\end{array}$ & Krisna & $\begin{array}{c}\text { Black } \\
\text { cofeea }\end{array}$ & $\begin{array}{l}\text { Kemasan } \\
\text { dus }\end{array}$ & \\
\hline 1 & 400 & 800 & 1000 & 600 & 220 & 300 & 220 & 300 & 3840 \\
\hline 2 & 300 & 600 & 1000 & 600 & 200 & 300 & 200 & 300 & 3500 \\
\hline 3 & 400 & 800 & 800 & 600 & 210 & 200 & 200 & 200 & 3410 \\
\hline 4 & 400 & 400 & 1000 & 500 & 200 & 300 & 210 & 300 & 3310 \\
\hline 5 & 400 & 800 & 900 & 600 & 200 & 300 & 200 & 300 & 3700 \\
\hline 6 & 400 & 800 & 1000 & 600 & 300 & 300 & 200 & 200 & 3800 \\
\hline 7 & 300 & 600 & 1000 & 600 & 200 & 200 & 200 & 300 & 3400 \\
\hline 8 & 400 & 800 & 1000 & 600 & 200 & 300 & 200 & 300 & 3800 \\
\hline 9 & 400 & 800 & 1000 & 500 & 200 & 300 & 220 & 300 & 3720 \\
\hline 10 & 400 & 800 & 900 & 600 & 220 & 300 & 200 & 200 & 3620 \\
\hline 11 & 400 & 800 & 1000 & 600 & 200 & 200 & 200 & 300 & 3700 \\
\hline 12 & 400 & 800 & 1000 & 600 & 200 & 300 & 200 & 300 & 3800 \\
\hline Jumlah & 4600 & 8800 & 11600 & 7000 & 2550 & 3300 & 2450 & 3300 & 43.600 \\
\hline
\end{tabular}

Penelitian ini bertujuan untuk menentukan jumlah produksi kopi yang optimal untuk mendapatkan keuntungan yang maksimum.

\section{METODE PENELITIAN}

\section{Program Linier}

Menurut Mulyono (2004) Program linear (Linear Programming yang disingkat LP) merupakan salah satu teknik Operating Research yang digunakan paling luas dan diketahui dengan baik.

Fungsi tujuan :

$$
\operatorname{Min}(\operatorname{Max}) \mathrm{Z}=\sum_{j=1}^{n} c_{j} x_{j}
$$

Fungsi batasan :

$$
\begin{aligned}
& \sum_{j=1}^{n} a_{i j} x_{j}\left(\begin{array}{l}
\leq \\
\vdots \\
\geq
\end{array}\right) b_{i} ; i=1,2,3, \ldots, m \\
& x_{j} \geq a_{; j}=1,2,3, \ldots, n
\end{aligned}
$$

\section{Program Dinamik}

Menurut Dimyati (1999), program dinamis adalah suatu teknik matematis yang biasannya digunakan untuk membuat suatu keputusan dari serangkaian keputusan yang saling berkaitan.Pendekatan rekursif maju adalah pendekatan yang penyelesaiannya dimulai dari 
tahap 1, maju ke tahap 2,3,.., $n$. Runtunan peubah keputusan adalah $x_{1}, x_{2}, x_{3}, \ldots ., x_{n}$. Pendekatan rekursif mundur adalah pendekatan yang penyelesaiannya dimulai dari tahap $n$, mundur ke tahap $n-1, n-2$ dan seterusnya sampai tahap 1 . Runtunan peubah keputusan adalah $x_{n}, x_{n-1}, \ldots, x_{1}$.

\section{Kopi}

Kopi adalah sejenis minuman yang berasal dari proses pengolahan dan ekstraksi biji tanaman kopi. Kata kopi awalnya berasal dari bahasa Turki "Kahveh" yang diambil dari bahasa Arab "Qahwah". Kahveh bukanlah nama tanamannya tapi sudah menjadi nama minumannya, yang artinya anggur dalam bahasa Arab. Kopi digolongkan kedalam famili rubiaceae dengan genus coffea. Secara umum kopi hanya memiliki dua spesies yaitu coffea arabica dan coffea robusta (Saputra E, 2008).

\section{Kerangka Konsep}

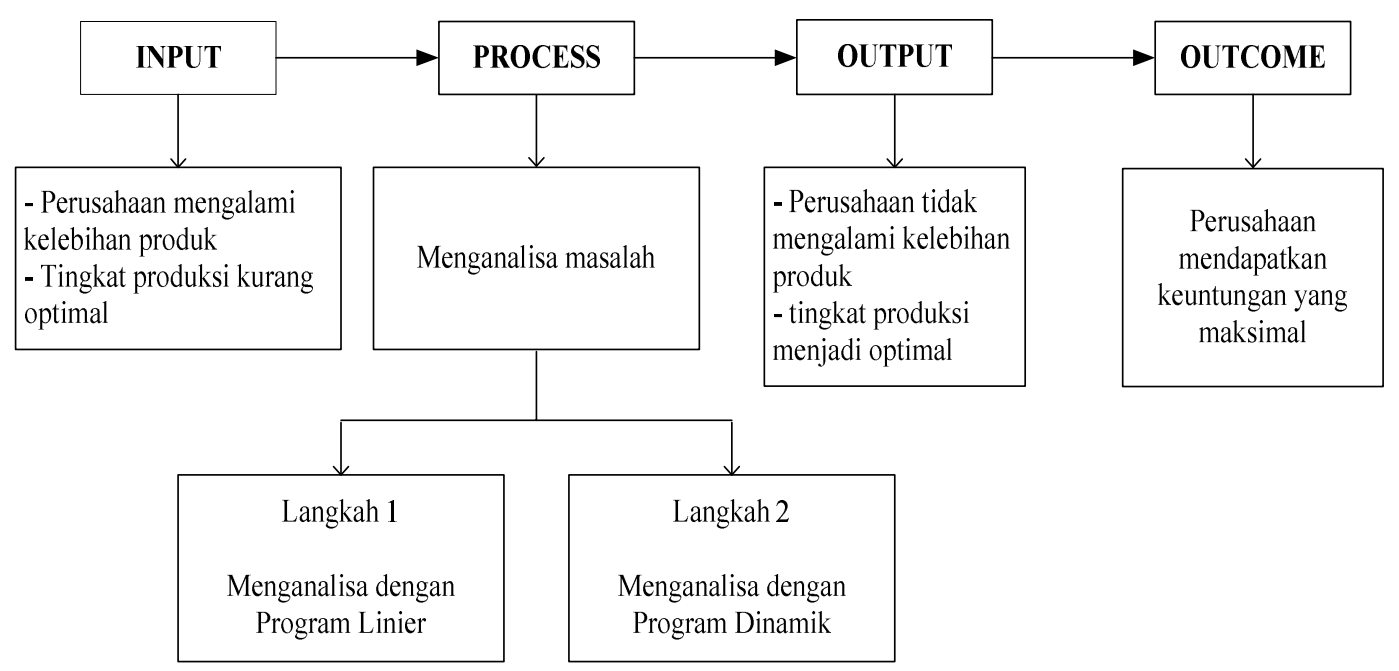

\section{Gambar : 1. Kerangka Konseptual}

\section{HASIL DAN PEMBAHASAN}

\section{Perhitungan LP dan DP}

Asumsi:

$x_{1}=$ jumlah kopi aroma per satuan gram

$x_{2}=$ jumlah kopi robusta aluminium foil per satuan gram

$x_{3}=$ jumlah kopi robusta plastik per satuan gram

$x_{4}=$ jumlah kopi jahe plastik per satuan gram

$x_{5}=$ jumlah kopi jahe toples per satuan gram

$x_{6}=$ jumlah kopi krisna per satuan gram

$x_{7}=$ jumlah kopi black coffea per satuan gram

$x_{8}=$ jumlah kopi kemasan dus per satuan gram

Maka dari asumsi diatas dapat dibuat:

1. Model fungsi tujuan:

$$
\operatorname{Max} f=19 x_{1}+13 x_{2}+10 x_{3}+14 x_{4}+18 x_{5}+18 x_{6}+20 x_{7}+20 x_{8} \text { (dalam ribuan) }
$$

2. Model kendala bahan baku:

$x_{1}+x_{2}+x_{3}+x_{4}+x_{5}+x_{6}+x_{7}+x_{8}=1.138$

3. Model kendala persediaan bahan baku: 


$$
\begin{aligned}
& x_{1} \leq 2.300 \\
& x_{2} \leq 4.400 \\
& x_{3} \leq 5.800 \\
& x_{4} \leq 3.500 \\
& x_{5} \leq 1.275 \\
& x_{6} \leq 1.650 \\
& x_{7} \leq 1.225 \\
& x_{8} \leq 1.650
\end{aligned}
$$

4. Model kendala permintaan pasar:

$$
x_{1}+x_{2}+x_{3}+x_{4}+x_{5}+x_{6}+x_{7}+x_{8} \leq 21.800
$$

model Program Linier menjadi:

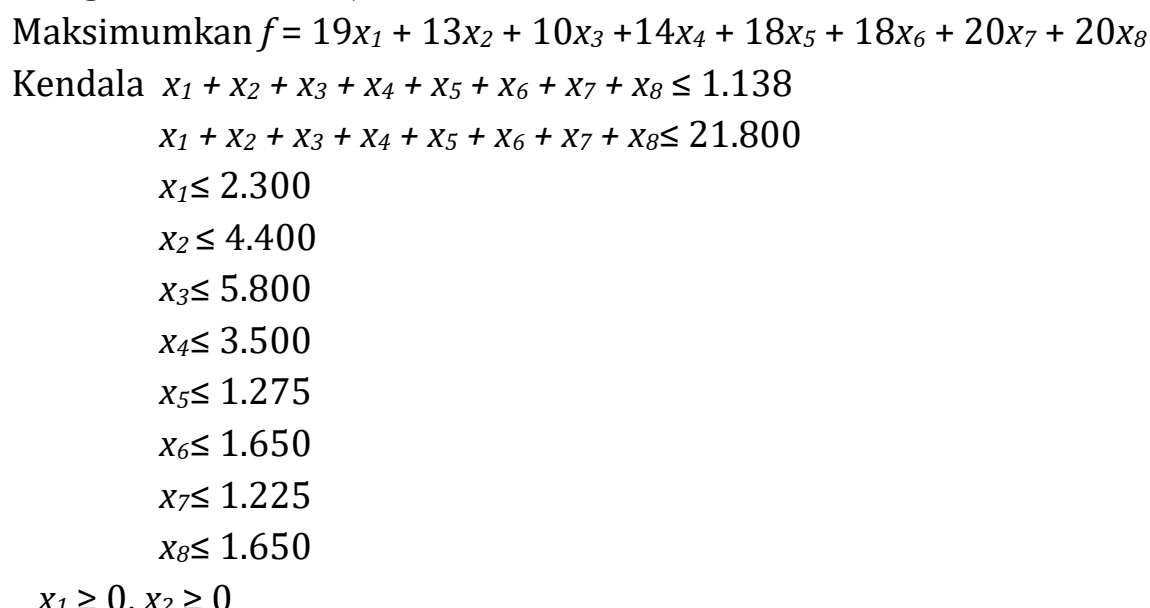

\section{Langkah 1:}

Dicari $B_{8}^{*}=\min \left(\frac{B_{18}}{1}, \frac{B_{98}}{1}, \frac{B_{28}}{0}, \frac{B_{48}}{0}, \frac{B_{58}}{0}, \frac{B_{68}}{0}, \frac{B_{78}}{0}, \frac{B_{88}}{0}, \frac{B_{98}}{0}, \frac{B_{198}}{1}\right)$

Dimana:

$$
\begin{aligned}
& B_{18}=1.138-x_{1}-x_{2}-x_{3}-x_{4}-x_{5}-x_{6}-x_{7} \\
& B_{28}=21.800-x_{1}-x_{2}-x_{3}-x_{4}-x_{5}-x_{6}-x_{7} \\
& B_{38}=2.300-x_{1} \\
& B_{48}=4.400-x_{2} \\
& B_{58}=5.800-x_{3} \\
& B_{68}=3.500-x_{4} \\
& B_{78}=1.275-x_{5} \\
& B_{88}=1.650-x_{6} \\
& B_{98}=1.225-X_{7} \\
& B_{108}=1.650 \\
& 0 \leq x_{8} \leq B_{8}^{*} \\
& =20 \mathrm{~min}\left(\frac{B_{1 E}}{1}, \frac{B_{2 E}}{1}, \frac{B_{9 E}}{0}, \frac{B_{4 E}}{0}, \frac{B_{5 E}}{0}, \frac{B_{6 E}}{0}, \frac{B_{7 E}}{0}, \frac{B_{9 E}}{0}, \frac{B_{9 E}}{0}, \frac{B_{10 E}}{1}\right)
\end{aligned}
$$

\section{Langkah 2:}

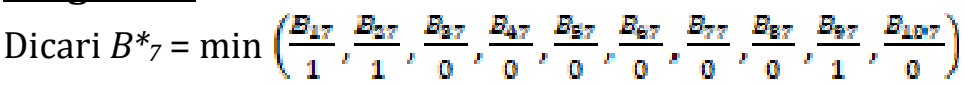

Dimana:

$B_{17}=1.138-x_{1}-x_{2}-x_{3}-x_{4}-x_{5}-x_{6}-x_{8}$

$B_{27}=21.800-x_{1}-x_{2}-x_{3}-x_{4}-x_{5}-x_{6}-x_{8}$ 


$$
\begin{aligned}
& B_{37}=2.300-x_{1} \\
& B_{47}=4.400-x_{2} \\
& B_{57}=5.800-x_{3} \\
& B_{67}=3.500-x_{4} \\
& B_{77}=1.275-x_{5} \\
& B_{87}=1.650-x_{6} \\
& B_{97}=1.225 \\
& B_{107}=1.650-x_{8}
\end{aligned}
$$

Dan,

$B_{7}\left(B_{17}, B_{27}, B_{37}, B_{47}, B_{57}, B_{67}, B_{77}, B_{87}, 8107\right)=\max 20 x_{7}$

$$
0 \leq x_{7} \leq B^{*}
$$

$$
=20 \min \left(\frac{B_{17}}{1}, \frac{B_{27}}{1}, \frac{B_{37}}{0}, \frac{B_{47}}{0}, \frac{B_{57}}{0}, \frac{B_{67}}{0}, \frac{B_{77}}{0}, \frac{B_{27}}{0}, \frac{B_{57}}{1}, \frac{B_{107}}{0}\right)
$$

\section{Langkah 3:}

Dicari $B_{6}^{*}=\min \left(\frac{B_{16}}{1}, \frac{E_{26}}{1}, \frac{B_{26}}{0}, \frac{B_{46}}{0}, \frac{B_{55}}{0}, \frac{B_{65}}{0}, \frac{B_{76}}{0}, \frac{E_{86}}{1}, \frac{B_{96}}{0}, \frac{B_{106}}{0}\right)$

Dimana:

$$
\begin{aligned}
& B_{16}=1.138-x_{1}-x_{2}-x_{3}-x_{4}-x_{5}-x_{7}-x_{8} \\
& B_{26}=21.800-x_{1}-x_{2}-x_{3}-x_{4}-x_{5}-x_{7}-x_{8} \\
& B_{36}=2.300-x_{1} \\
& B_{46}=4.400-x_{2} \\
& B_{56}=5.800-x_{3} \\
& B_{66}=3.500-x_{4} \\
& B_{76}=1.275-x_{5} \\
& B_{86}=1.650 \\
& B_{96}=1.225-x_{7} \\
& B_{106}=1.650-x_{8}
\end{aligned}
$$

Dan,

$B_{6}\left(B_{16}, B_{26}, B_{36}, B_{46}, B_{56}, B_{66}, B_{76}, B_{96}, B_{106}\right)=\max 18 x_{6}$

$$
0 \leq x_{6} \leq B_{6}^{*}
$$

$$
=18 \min \left(\frac{B_{16}}{1}, \frac{B_{96}}{1}, \frac{B_{96}}{0}, \frac{B_{46}}{0}, \frac{B_{56}}{0}, \frac{B_{66}}{0}, \frac{B_{76}}{0}, \frac{B_{96}}{1}, \frac{B_{96}}{0}, \frac{B_{106}}{0}\right)
$$

\section{Langkah 4:}

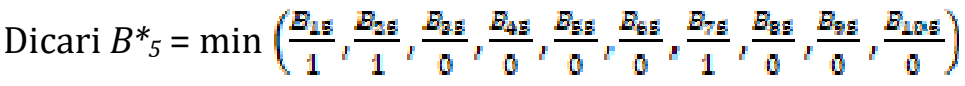

Dimana:

$$
\begin{aligned}
& B_{15}=1.138-x_{1}-x_{2}-x_{3}-x_{4}-x_{6}-x_{7}-x_{8} \\
& B_{25}=21.800-x_{1}-x_{2}-x_{3}-x_{4}-x_{6}-x_{7}-x_{8} \\
& B_{35}=2.300-x_{1} \\
& B_{45}=4.400-x_{2} \\
& B_{55}=5.800-x_{3} \\
& B_{65}=3.500-x_{4} \\
& B_{75}=1.275 \\
& B_{85}=1.650-x_{6} \\
& B_{95}=1.225-x_{7} \\
& B_{105}=1.650-x_{8}
\end{aligned}
$$

Dan,

$B_{5}\left(B_{15}, B_{25}, B_{35}, B_{45}, B_{55}, B_{65}, B_{85}, B_{95}, B_{105}\right)=\max 18 x_{5}$ 


$$
=18 \min \left(\frac{B_{1 I}}{1}, \frac{B_{2 I}}{1}, \frac{B_{2 I}}{0}, \frac{B_{4 I}}{0}, \frac{B_{3 I}}{0}, \frac{B_{6 I}}{0}, \frac{B_{7 I}}{1}, \frac{B_{2 I}}{0}, \frac{B_{4 I}}{0}, \frac{B_{10 \mathrm{I}}}{0}\right)
$$

\section{Langkah 5:}

Dicari $B^{*}=\min \left(\frac{B_{14}}{1}, \frac{B_{24}}{1}, \frac{B_{84}}{0}, \frac{B_{44}}{0}, \frac{B_{54}}{0}, \frac{B_{54}}{1}, \frac{B_{74}}{0}, \frac{B_{84}}{0}, \frac{B_{94}}{0}, \frac{B_{104}}{0}\right)$

Dimana:

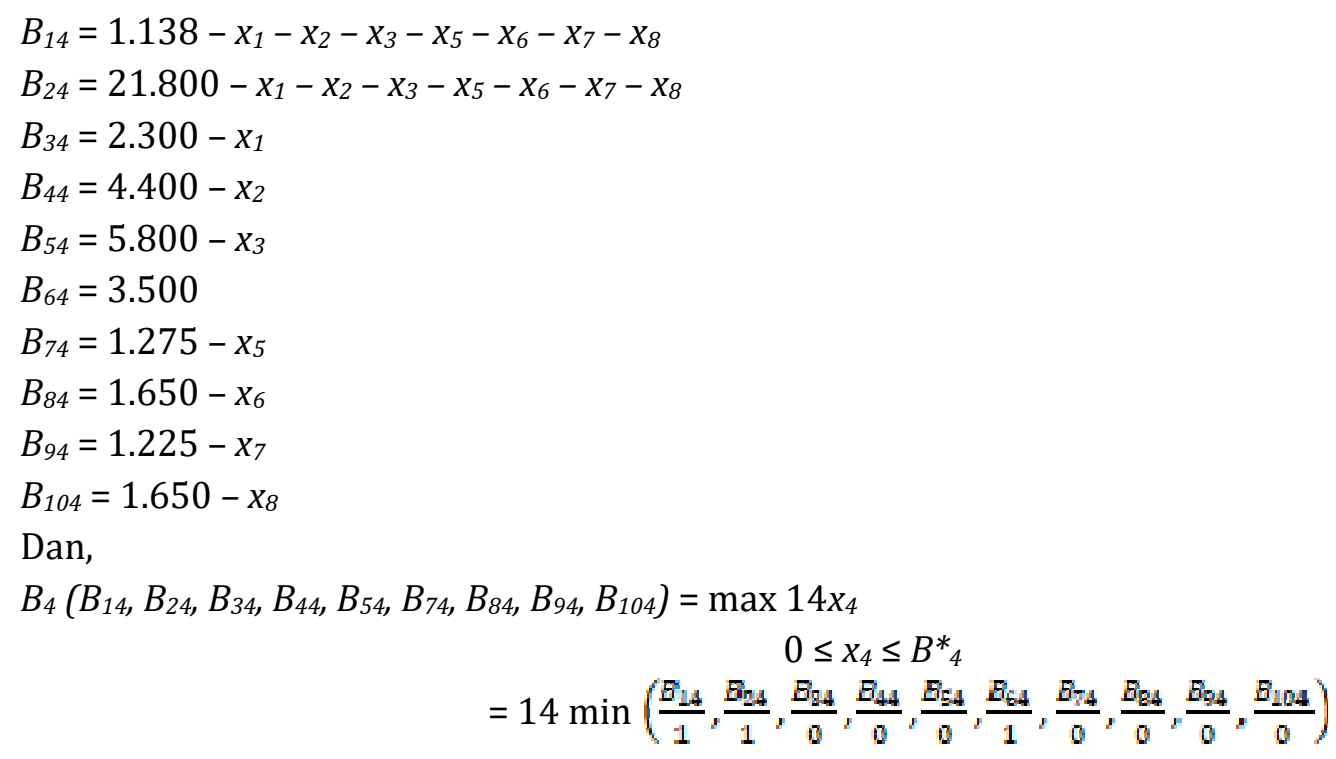

\section{Langkah 6:}

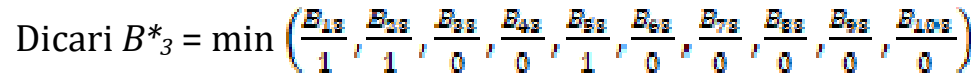

Dimana:

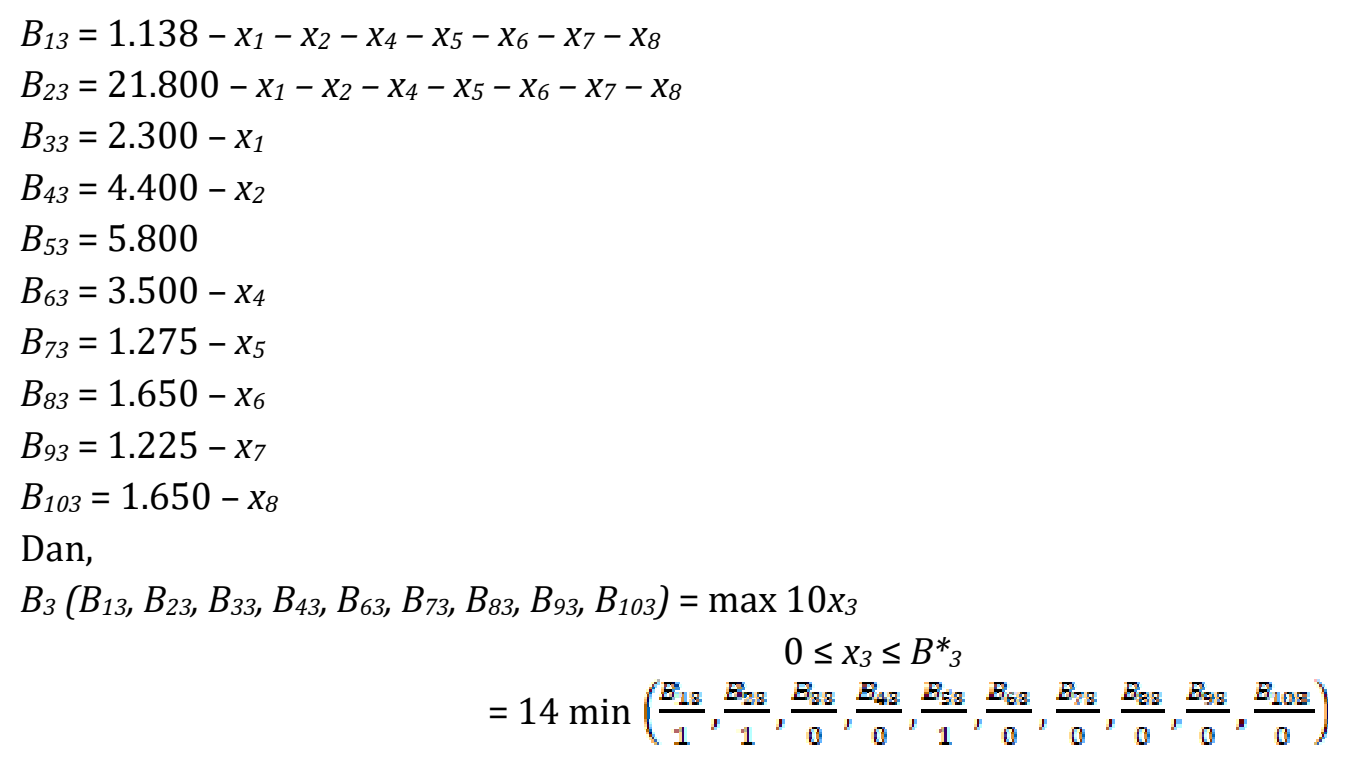

\section{Langkah 7:}

Dicari $B^{*}=\min \left(\frac{B_{12}}{1}, \frac{B_{2 n}}{1}, \frac{B_{2 n}}{0}, \frac{B_{42}}{1}, \frac{B_{5 n}}{0}, \frac{B_{5 n}}{0}, \frac{B_{7 n}}{0}, \frac{B_{9 n}}{0}, \frac{B_{9 n}}{0}, \frac{B_{10 n}}{0}\right)$

Dimana:

$$
\begin{aligned}
& B_{12}=1.138-x_{1}-x_{3}-x_{4}-x_{5}-x_{6}-x_{7}-x_{8} \\
& B_{22}=21.800-x_{1}-x_{3}-x_{4}-x_{5}-x_{6}-x_{7}-x_{8} \\
& B_{32}=2.300-x_{1} \\
& B_{42}=4.400
\end{aligned}
$$




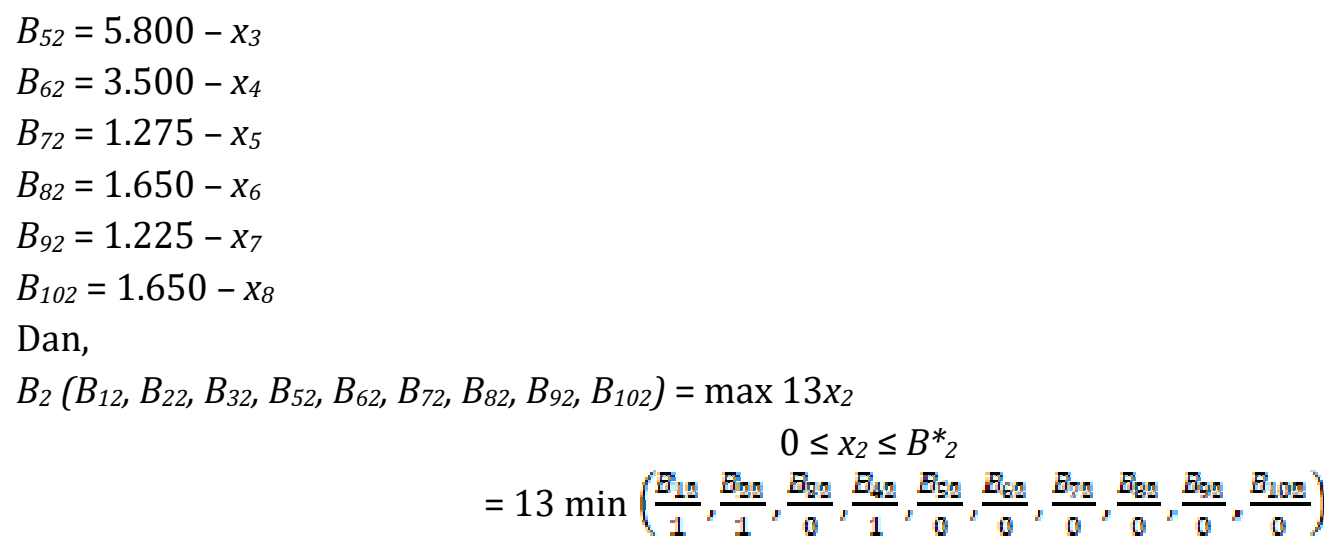

\section{Langkah 8:}

Dicari $B^{*}{ }_{1}=\min \left(\frac{B_{11}}{1}, \frac{B_{21}}{1}, \frac{B_{31}}{1}, \frac{E_{41}}{0}, \frac{B_{31}}{0}, \frac{B_{61}}{0}, \frac{B_{71}}{0}, \frac{B_{81}}{0}, \frac{B_{91}}{0}, \frac{B_{181}}{0}\right)$

Karena ini adalah tahap terakhir, maka:

$$
\begin{aligned}
& B_{11}=1.138 \\
& B_{21}=21.800 \\
& B_{31}=2.300 \\
& B_{41}=4.400 \\
& B_{51}=5.800 \\
& B_{61}=3.500 \\
& B_{71}=1.275 \\
& B_{81}=1.650 \\
& B_{91}=1.225 \\
& B_{101}=1.650
\end{aligned}
$$

Jadi, $B^{*}{ }_{1}=\min \left(\frac{1.138}{1}, \frac{21.800}{1}, \frac{2,300}{1}, \infty\right)=1.138$

Sehingga:

$f_{1}\left(B_{11}, B_{21}, B_{31}, B_{41}, B_{51}, B_{61}, B_{71}, B_{81}, B_{91}, B_{101}\right)=\max 19 x_{1}+13 \times 2+10 \times 3+14 \times 4+18 \times 5+18 \times 6+$ $20 \times 7+20 \min \left(\frac{B_{1 n}}{1}, \frac{B_{n n}}{1}, \frac{B_{2 n}}{0}, \frac{B_{4 n}}{1}, \frac{B_{5 n}}{0}, \frac{B_{6 n}}{0}, \frac{B_{n n}}{0}, \frac{B_{2 n}}{0}, \frac{B_{9 n}}{0}, \frac{B_{19 n}}{0}\right)$

$$
0 \leq x_{1} \leq 1.138
$$

Berdasarkan perhitungan diatas, solusi dari masalah diatas adalah $x_{1}=0, x_{2}=0, x_{3}=0, x_{4}=$ $0, x_{5}=0, x_{6}=0, x_{7}=1.136, x_{8}=0, f=22.760 .000$. Artinya, perusahaan seharusnya memproduksi lebih banyak kopi jenis $x_{7}$ daripada kopi jenis lainnya. kopi jenis $x_{7}$ yaitu kopi Black Coffea dengan pendapatan optimum sebesar Rp. 22.760.000.

\section{Pola Perusahaan}

a. Tingkat produksi optimal kopi setiap bulannya adalah:

$$
\begin{aligned}
x & =\frac{\bar{x} \text { persedian } B E}{8} \\
& =\frac{1138}{8} \\
& =142 \text { bungkus }
\end{aligned}
$$

b. Pendapatan optimum kopi adalah sebesar:

$$
\begin{aligned}
f & =\Sigma \text { harga pokok } \times x \\
& =132.000 \times 142 \\
& =\text { Rp. } 18.744 .000
\end{aligned}
$$


Berdasarkan hasil perhitungan yang dilakukan pada sub bab sebelumnya, dapat disimpulkan bahwa tingkat produksi optimum kopi dengan teknik program linier dan program dinamik diperoleh sebesar 1.138 bungkus dengan pendapatan sebesar Rp. 22.760.000. tingkat produksi optimum berdasarkan pola produksi perusahaan sebesar 142 bungkus dengan pendapatan sebesar Rp. 18.744.000.

Perbandingan keputusan optimal perhitungan program dinamik dengan perhitungan perusahaan terlihat jumlah kopi yang diproduksi perbulan sesuai dengan jumlah permintaan pada bulan tersebut, maka biaya pendapatan perbulannya adalah Rp. 22.760.000.

Bila biaya produksi dengan perhitungan program dinamik dibandingkan dengan perhitungan perusahaan, maka akan terjadi peningkatan pendapatan penjualan sebesar:

= Perhitungan dengan teknik program dinamik - pola produksi perusahaan

$=$ Rp. $22.760 .000-18.744 .000$

$=$ Rp. 4.016 .000

Dari hasil tersebut dapat dilihat bahwa perencanaan dengan menggunakan program dinamik ternyata lebih menguntungkan.

\section{KESIMPULAN}

Berdasarkan hasil penelitian dan analisis data pada bab-bab sebelumnya, maka dapat disimpulkan bahwa untuk mendapatkan tingkat produksi kopi yang optimal dan pendapatan yang maksimal perusahaan harus menggunakan metode program linier dan program dinamik. Dengan menggunakan program linier dan program dinamik tingkat produksi kopi menjadi optimal dan tingkat pendapatan juga optimal, dengan tingkat produksi kopi sebesar 1.138 bungkus (kopi jenis Black Coffea) dengan pendapatan sebesar Rp. 22.760.000 perbulan.

\section{DAFTAR PUSTAKA}

Andi, R. B, dkk. 2013. Optimasi Produksi dengan Program Dinamis pada Pabrik Fractination and Refinery Factory (FRF) PT. XYZ. E-Jurnal Teknik Industri FT USU. Vol. 3 No. 4. Pp. 49-54.

Dimyati, T. T., \& Dimyati, A. (1999). Operations Research, Model-model Pengambilan Keputusan. Bandung: Sinar Baru Algesindo.

Fauzi, A., Mas'ud, M. I. (2019). Proses Manufaktur pada Mesin Primer dan Sekunder CV. Karunia Menggunakan Metode Linier Programming. Journal Knowledge Industrial Engineering (JKIE), 6(2), 59-65. https://doi.org/10.35891/jkie.v6i2.2055

Junaedi, D., Mas'ud, M. I. (2018). Penerapan Metode Forecasting dalam Perencanaan Produksi Bakpia dengan Menggunakan Software POM Guna Memenuhi Permintaan Konsumen. Journal Knowledge Industrial Engineering (JKIE), 5(3), 121-128. https://doi.org/10.35891/jkie.v5i3.2042

Mas'ud, M. I. (2016). Pendekatan Rantai Markov Dalam Pemilihan Universitas Di Kabupaten

Pasuruan. Journal Knowledge Industrial Engineering (JKIE), 4(1), 63-70

Mulyono, S. (2004). Riset Operasi. Jakarta: Penerbitan Fakultas Ekonomi Universitas Indonesia.

Santoso, B. 1999. Pendugaan Fungsi Keuntungan dan Skala Usaha pada Usaha Tani Kopi Rakyat di Lampung, Pusat Penelitian Agro Ekonomi, Bogor.

Roland, G. S, dkk. 2013. Aplikasi Program Dinamik untuk Mengoptimalkan Biaya Total pada

Pengendalian Produksi Minyak Sawit dan Inti Sawit (Studi Kasus: PTPN IV (Persero) PKS

Sawit Langkat). Jurnal Saintia Matematika. Vol. 1 No. 5. Pp. 419-433.

Saputra, E., 2008. Kopi. Harmoni, Yogyakarta. 